\title{
狮牙草状风毛菊果期资源分配对海拔的响应
}

\author{
李 蕾 王一峰* 苟文霞 马文梅 蒋春玲
}

西北师范大学生命科学学院, 兰州 730070

\begin{abstract}
摘 要 植物资源分配是目前植物生态学研究的热点问题, 主要集中在性分配和繁殖分配两个方面。该研究以分布在青藏 高原的狮牙草状风毛菊(Saussurea leontodontoides)作为研究材料, 研究了6个海拔高度上果期植株的繁殖特征及资源分配的 差异, 并用异速模型分析了繁殖性状及资源分配与个体大小的关系。结果显示: 1)狮牙草状风毛菊的个体大小、繁殖器官生 物量、营养器官生物量、种子数和营养分配均与海拔存在极显著负相关关系, 百粒质量和繁殖分配与海拔存在极显著正相关 关系。2)在不同海拔高度下, 百粒质量、种子数、繁殖器官生物量及营养分配与植株个体大小呈正相关关系; 繁殖分配与植 株个体大小呈负相关关系; 而营养器官生物量与植株个体大小呈极显著正相关关系。这表明海拔和个体大小对狮牙草状风毛 菊的繁殖对策有不同程度的影响，狮牙草状风毛菊通过增加繁殖部分的生物量和百粒质量来适应高海拔的胁迫环境。

关键词 海拔; 狮牙草状风毛菊; 异速模型; 繁殖分配
\end{abstract}

李蕾, 王一峰, 苟文霞, 马文梅, 蒋春玲 (2020). 狮牙草状风毛菊果期资源分配对海拔的响应. 植物生态学报, 44, 1164-1171. DOI: 10.17521/cjpe.2020.0201

\section{Response of resource allocation of Saussurea leontodontoides during its fruiting stage to the elevation}

LI Lei, WANG Yi-Feng*, GOU Wen-Xia, MA Wen-Mei, and JIANG Chun-Ling

College of Life Sciences, Northwest Normal University, Lanzhou 730070, China

\section{Abstract}

Aims Our objective is to study the differences between the reproduction characteristics and resource allocation of Saussurea leontodontoides in the fruiting stage across six levels of the elevation gradient, and analyze the relationship between the above two parameters and individual size of S. leontodontoides.

Methods The study site is located in the northeastern margin of the Qingzang Plateau. The collection and investigation were carried out on the fruiting individuals of S. leontodontoides which were distributed in an elevation range of $3200-4540 \mathrm{~m}$. 40 complete individuals were randomly collected from each level of the elevation. The number of seeds in each capitulum was counted, then the biomass was measured after drying at $80^{\circ} \mathrm{C}$ in the oven. The differences between the reproduction characteristics and resource allocation of $S$. leontodontoides at different levels of the elevation gradient were analyzed by ANOVA. The relationship between the reproduction characteristics with individual size, resource allocation with individual size at different levels of the elevation gradient was analyzed by the allometric model.

Important findings Our results showed that: 1) The individual size, reproductive organ biomass, vegetative organ biomass, seed number and vegetative allocation were negatively correlated with elevation; the hundred grain mass and reproductive allocation were positively correlated with elevation. 2) Along the elevation gradient, the hundred grain mass, the seed number, the reproductive organs biomass and the vegetative allocation were positively correlated with individual size; reproductive allocation was negatively related to individual size; and vegetative organ biomass and individual size were significantly positively correlated. This indicates that the elevation and individual size had different effects on the reproductive strategy of S. leontodontoides. Our study suggests that $S$. leontodontoides adapted to the high-elevation stress environment by increasing the reproductive organs biomass and the hundred grain mass.

Key words elevation; Saussurea leontodontoides; allometric model; reproductive allocation

Li L, Wang YF, Gou WX, Ma WM, Jiang CL (2020). Response of resource allocation of Saussurea leontodontoides during its fruiting stage to the elevation. Chinese Journal of Plant Ecology, 44, 1164-1171. DOI: 10.17521/cjpe.2020.0201

收稿日期Received: 2020-06-19 接受日期Accepted: 2020-10-12

基金项目: 国家自然科学基金(31460105)。Supported by the National Natural Science Foundation of China (31460105).

* 通信作者Corresponding author(1930855928@qq.com) 
植物可利用的有效资源总量是有限的，用于某 一性状(器官)的资源量增加必然会导致用于其他性 状资源量的减少。对有限的资源进行配置存在于植 物的整个生长发育阶段中(靳瑰丽, 2009)。植物繁殖 阶段对环境变化尤为敏感, 植物在生长发育过程中, 难以避免会受到外界因素以及内部环境的影响, 而 外界因素对植物生长发育的影响可能大于内部环境 对植物生长发育的影响(王会霞, 2012)。海拔是影响 植物生长发育的综合环境因子, 往往伴随着气温、 湿度、辐射等环境因素的变化, 而环境因子的这一 系列变化会导致植物的资源配置发生改变(Sakai et al., 2006; Milla et al., 2009; 索南措等, 2013; 陈凯 等, 2020)。植物对资源的不同分配模式反映了植物 在不同选择压力下的生活史对策(王天慧, 2006)。研 究物种的生活史特征变化在理解特定类型的生态压 力对植物繁殖策略调整方面有重要作用, 植物通常 选择以最优的分配模式适应环境的变化, 以提高适 合度, 保证种群的成功繁殖。

繁殖是生物为延续种族所进行的产生后代的生 理过程, 是物种进化发展的主要原因。繁殖分配是 植物分配给繁殖活动的资源量, 即植物为保证种族 的延续而分配给繁殖的资源分配比例 (张大勇, 2000)。Fenner (1985)认为繁殖分配是物种特有的、 为应对各种生存困难，整体性状相互协同的现象。 繁殖分配因物种的不同而不同, 主要受到自然选择 和植物形态的影响(Tamagno et al., 2020)。Wilson和 Thompson (1989)分析了温室条件下40种草本植物 的繁殖分配, 发现 8 种一年生植物在生长的第一年 开花, 并且保持着较高的繁殖分配比例, 然而在干 旱、营养缺乏的生境中多年生植物两年才能开花, 且繁殖分配比例较低。侯勤正(2016)、操国兴(2005) 认为种群间的繁殖分配差异不仅与不同的群落演替 状况有关, 还与植物个体大小存在紧密的联系。

在国内外, 已有很多有关青藏高原高寒草甸植 被资源分配的研究报道, 其中对禾本科、龙胆属 (Gentiana)及风毛菊属(Saussurea) 等植物的研究报 道相对较多(侯勤正等, 2017; 王素玉, 2017)。风毛菊 属植物种类丰富, 有 400 余种, 重点分散在亚洲与欧 洲的高海拔地区, 大多生长在河滩地、高山草甸、 灌从以及石缝等生境中, 能适应高山地区复杂的环 境气候, 并具有在比较极端的环境中生存的能力。 近年来, 对风毛菊属植物资源分配的研究涉及重齿
风毛菊(Saussurea katochaete)、弯齿风毛菊(Saussurea przewalskii)、星状雪兔子(Saussurea stella)、甘肃风 毛菊(Saussurea kansuensis)、波缘风毛菊(Saussurea undulata)、大耳叶风毛菊(Saussurea macrota)等多个 物种(王一峰等, 2012, 2014, 2017; 陈亭和王一峰, 2014; 毛婉嫕等, 2019; 祁如林等, 2019)。但以上关 于风毛菊属植物的研究主要集中在花期资源分配与 海拔高度的相关性方面, 目前还未见单独对狮牙草 状风毛菊(Saussurea leontodontoides)果期资源分配 与海拔的相关性研究。本研究以青藏高原 6 个不同海 拔的果期狮牙草状风毛菊为研究对象, 探究以下问 题: 1)海拔对果期狮牙草状风毛菊各生物量的影响; 2)海拔对各生物量的影响是依赖于个体大小还是独 立于个体大小? 我们期望通过此次研究, 阐明海拔 对狮牙草状风毛菊的果期繁殖性状及资源分配的影 响机制, 继而深入认识高寒草甸植物的生活史特征 及植物对高寒环境的适应对策, 为高寒草甸植被的 开发利用提供一定的理论依据。

\section{1 材料和方法}

\section{1 研究区概况}

供试用狮牙草状风毛菊样品于同一时期(盛果 期)采自青藏高原东缘的合作市和玛曲县, 青藏高 原东北边缘的湟源县、兴海县和玛多县, 青藏高原 中部的治多县。

合作市和玛曲县位于甘肃省甘南藏族自治州, 地理位置介于 $100.77^{\circ}-104.73^{\circ} \mathrm{E} 、 33.1^{\circ}-36.17^{\circ} \mathrm{N}$ 之 间, 该地区的地势西北高东南低, 海拔高度为 1200-5 200 m, 年降水量为500-800 mm, 年平均气 温为 $1.7{ }^{\circ} \mathrm{C}$, 属于高原大陆性气候; 湟源县位于青 海省西宁市, 地理位置介于 $100.9^{\circ}-101.42^{\circ} \mathrm{E}$ 、 $36.33^{\circ}-36.88^{\circ} \mathrm{N}$ 之间，该地区地势由北向南倾斜, 西北高, 东南低, 东西狭长, 海拔高度为 $2470-$ $4898 \mathrm{~m}$, 年降水量为 $408.9 \mathrm{~mm}$, 年平均气温为 $3{ }^{\circ} \mathrm{C}$, 属于大陆性高原半干旱气候; 兴海县位于青海省海 南藏族自治州，地理位置介于 $98.92^{\circ}-105.83^{\circ} \mathrm{E}$ 、 $34.63^{\circ}-37.17^{\circ} \mathrm{N}$ 之间, 该区地势起伏较大, 平均海 拔在 $3000 \mathrm{~m}$ 以上, 年平均气温在 $4{ }^{\circ} \mathrm{C}$ 左右, 属于典 型的高原大陆性气候区; 玛多县位于果洛藏族自治 州, 地理位置介于 $97.9^{\circ}-101.83^{\circ} \mathrm{E} 、 32.52^{\circ}-35.67^{\circ} \mathrm{N}$ 之间, 该区地形自西北向东南倾斜, 平均海拔在 $4000 \mathrm{~m}$ 以上, 年平均气温在 $-4{ }^{\circ} \mathrm{C}$, 属于高寒草原 
表1 狮牙草状风毛菊采样地概况

Table 1 Sampling sites of Saussurea leontodontoides

\begin{tabular}{|c|c|c|c|c|c|c|}
\hline $\begin{array}{c}\text { 种群数量 } \\
\text { Population number }\end{array}$ & $\begin{array}{c}\text { 采集时间 } \\
\text { Collection date }\end{array}$ & $\begin{array}{c}\text { 海拔 } \\
\text { Altitude (m) }\end{array}$ & $\begin{array}{l}\text { 经纬度 } \\
\text { Latitude and longitude }\end{array}$ & $\begin{array}{l}\text { 采样地 } \\
\text { Sampling site }\end{array}$ & $\begin{array}{l}\text { 生境类型 } \\
\text { Habitat Type }\end{array}$ & $\begin{array}{c}\text { 样本数 } \\
\text { Sample size }\end{array}$ \\
\hline 1 & $2018-08-26$ & 3200 & $102.89^{\circ} \mathrm{E}, 34.91^{\circ} \mathrm{N}$ & $\begin{array}{l}\text { 合作市电视塔山 } \\
\text { TV Tower Mountain in Hezuo }\end{array}$ & $\begin{array}{l}\text { 山坡草甸 } \\
\text { Hillside meadow }\end{array}$ & 40 \\
\hline 1 & $2017-08-30$ & 3490 & $101.11^{\circ} \mathrm{E}, 36.43^{\circ} \mathrm{N}$ & $\begin{array}{l}\text { 湟源县日月山 } \\
\text { Riyue Mountain, Huangyuan }\end{array}$ & $\begin{array}{l}\text { 山坡草甸 } \\
\text { Hillside meadow }\end{array}$ & 40 \\
\hline 1 & $2018-08-28$ & 3690 & $101.69^{\circ} \mathrm{E}, 33.78^{\circ} \mathrm{N}$ & $\begin{array}{l}\text { 玛曲县阿万仓山 } \\
\text { Awancang Mountain, Maqu }\end{array}$ & $\begin{array}{l}\text { 山坡草甸 } \\
\text { Hillside meadow }\end{array}$ & 40 \\
\hline 1 & $2017-08-31$ & 3970 & $99.44^{\circ} \mathrm{E}, 35.40^{\circ} \mathrm{N}$ & $\begin{array}{l}\text { 兴海县温泉乡 } \\
\text { Wenquan Township, Xinghai }\end{array}$ & $\begin{array}{l}\text { 山坡草甸 } \\
\text { Hillside meadow }\end{array}$ & 40 \\
\hline 1 & $2017-08-31$ & 4260 & $98.21^{\circ} \mathrm{E}, 34.91^{\circ} \mathrm{N}$ & $\begin{array}{l}\text { 玛多县城 } \\
\text { Madoi County }\end{array}$ & $\begin{array}{l}\text { 山坡草甸 } \\
\text { Hillside meadow }\end{array}$ & 40 \\
\hline 1 & $2017-08-12$ & 4540 & $92.73^{\circ} \mathrm{E}, 34.45^{\circ} \mathrm{N}$ & $\begin{array}{l}\text { 治多县109国道旁 } \\
\text { Next to national highway } 109 \text { in Zhidoi }\end{array}$ & $\begin{array}{l}\text { 山坡草甸 } \\
\text { Hillside meadow }\end{array}$ & 40 \\
\hline
\end{tabular}

气候; 治多县位于玉树藏族自治州, 地理位置介于 $89.45^{\circ}-97.65^{\circ} \mathrm{E} 、 31.75^{\circ}-36.17^{\circ} \mathrm{N}$ 之间, 平均海拔在 $4200 \mathrm{~m}$ 以上, 年平均气温为 $-0.8{ }^{\circ} \mathrm{C}$, 属于高原气 候。样地内风毛菊属植物资源相对丰富, 为当地高 山草甸的建群种或优势种(王一峰, 2009)。

\section{2 研究材料}

“狮牙草状风毛菊为多年生草本植物, 多生于海 拔3 280-5 450 m山坡砾石地、林间砾石地、草地、 林缘、灌从边缘。根状茎有分枝。茎极短, 灰白色, 被 稠密的蛛丝状棉毛至无毛。叶莲座状, 有叶柄, 叶片 全形线状长椭圆形, 羽状全裂, 顶端圆形或针三角 形，全部裂片两面异色，上面绿色，被稀疏糙毛，下 面灰白色, 被稠密的线毛。头状花序单生于莲座状 叶丛中或莲座状之上。总苞宽钟状, 苞片无毛, 外层 及中层披针形, 顶端渐尖, 内层线形, 小花紫红色, 瘦果圆柱形, 有横皱纹。冠毛淡褐色, 2层, 外层短, 糙毛状; 内层长, 羽毛状。花果期8-10月” (石铸和 靳淑英, 1999)。

于 2018 年和 2019年 8-10月，对分布在海拔 3200-4540 m处于盛果期的狮牙草状风毛菊进行 采集调查, 在每个海拔高度随机采集 40 个完整植株, 由于在采样过程中植株的根系很难采集完整, 每个 植株均从地表剪取地上部分, 标号分装进袋, 带回 实验室。统计每株头状花序上的种子数目, 然后置 于 $80{ }^{\circ} \mathrm{C}$ 烘箱中烘 $24 \mathrm{~h}$ 。再用 $1 / 10000$ 的电子天平称 得植物地上部分总干质量、头状花序干质量、茎叶 总干质量和种子百粒质量(随机选取成熟度高且完 好的种子)。

\section{3 统计分析}

地上部分的生物量干质量表示植株个体大小,
茎叶总干质量表示营养器官生物量, 头状花序干质 量表示繁殖器官生物量; 繁殖器官生物量占地上部 分生物量干质量的比值表示繁殖分配; 营养器官生 物量占地上部分生物量干质量的比值表示营养分 配。利用单因素ANOVA和线性回归的方法分析个体 大小、繁殖器官质量、营养器官质量、百粒质量、 种子数、繁殖分配和营养分配在不同海拔下的相关 变异。采用异速方程: $Y=a x^{b}$, 分析不同海拔间植株 个体大小 $(x)$ 与资源分配及种子特征 $(Y)$ 的内在关系, 将变量 $\lg$ 转换后得到以下方程: $\lg Y=\lg a+b \lg x$ (其 中 $b$ 代表斜率, $\lg a$ 为截距), 在数据分析时对所用数 据进行了对数转换(包括种子数、百粒质量、营养器 官生物量、繁殖器官生物量、营养分配以及繁殖分 配)以消除变量偏差对回归系数造成的影响。采用回 归分析中的线性回归进行分析，若果期繁殖性状、 资源分配与个体大小在各海拔间异速关系均显著 $(p<0.05)$, 将个体大小作为协变量, 用一般线性模 型中的单变量比较不同海拔种群间 $\lg a$ 和 $b$ 的变化: 若是截距 $\lg a$ 在海拔间有显著的变化, 就表明海拔 效应显著; 若是斜率 $b$ 在海拔间有显著的变化, 就 表明海拔和协变量(个体大小)存在显著的交互作用, 说明繁殖性状的大小依赖性随着海拔的增高变化显 著。以上所有数据均采用Excel进行统计, SPSS 17.0 进行分析, 采用Origin 2017软件作图。

\section{2 结果和分析}

\section{1 繁殖特征与海拔的相关性}

由图1可以看出, 狮牙草状风毛菊的个体大小 与海拔高度存在极显著负相关关系 $(p<0.01)$, 即随 海拔的升高, 狮牙草状风毛菊的个体大小逐渐减 www.plant-ecology.com 
小。从海拔 $3200 \mathrm{~m}$ 处的 $5.39 \mathrm{~g}$ 逐渐减少到海拔 $4540 \mathrm{~m}$ 处的 $3.11 \mathrm{~g}$ 。

由图2可以看出, 狮牙草状风毛菊的繁殖器官 生物量和营养器官生物量均与海拔高度存在极显著 负相关关系 $(p<0.01)$, 即随海拔的升高, 狮牙草状 风毛菊对繁殖器官和营养器官的投资均逐渐减小。 分别从海拔 $3200 \mathrm{~m}$ 处的 $1.10 、 4.29 \mathrm{~g}$ 逐渐减少到海 拔 $4540 \mathrm{~m}$ 处的 $0.83 、 2.01 \mathrm{~g}$ 。

由图3可以看出，狮牙草状风毛菊的种子百粒 质量与海拔存在极显著正相关关系 $(p<0.01)$, 而种 子数与海拔存在极显著负相关关系 $(p<0.01)$, 即随 海拔升高, 狮牙草状风毛菊每株的种子百粒质量呈 增大的趋势, 而种子数量呈逐渐减小的趋势。种子 百粒质量从海拔 $3200 \mathrm{~m}$ 处的 $0.0398 \mathrm{~g}$ 逐渐增加到 海拔 $4540 \mathrm{~m}$ 处的 $0.0467 \mathrm{~g}$; 而种子数从海拔 3200 $\mathrm{m}$ 处的 323 粒逐渐减少到海拔 $4540 \mathrm{~m}$ 处的 251 粒。

由图4可以看出, 狮牙草状风毛菊的繁殖分配 与海拔存在极显著正相关关系 $(p<0.01)$, 营养分配

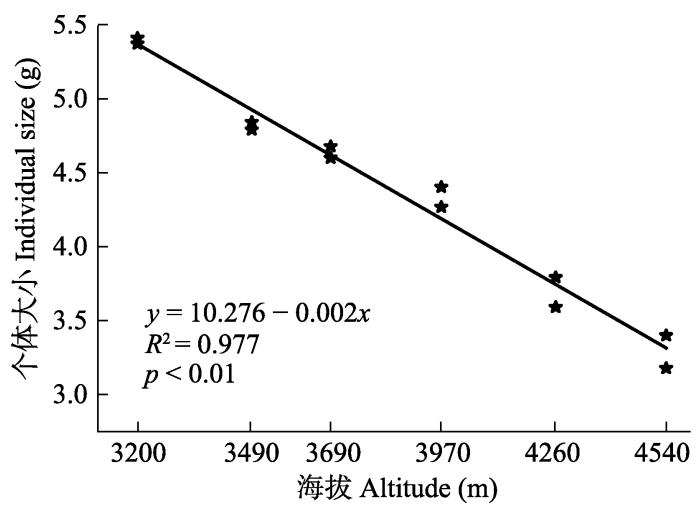

图1 狮牙草状风毛菊个体大小与海拔的线性回归关系。

Fig. 1 Liner regression between individual size and altitude for Saussurea leontodontoides.

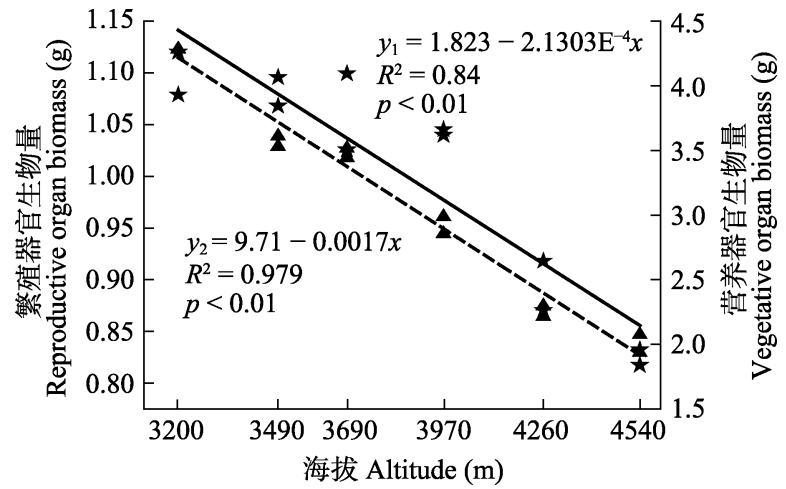

图2 狮牙草状风毛菊繁殖器官生物量 $\left(y_{1}, \star\right)$ 及营养器官生 物量 $\left(y_{2}, \mathbf{\Delta}\right)$ 与海拔 $(x)$ 的线性回归。

Fig. 2 Liner regression between reproductive organ biomass $\left(y_{1}, \star\right)$, vegetative organ biomass $\left(y_{2}, \mathbf{\Lambda}\right)$ and altitude $(x)$ for Saussurea leontodontoides.
与海拔存在极显著负相关关系 $(p<0.01)$, 即随海拔 的升高, 狮牙草状风毛菊对繁殖器官的相对资源投 入呈增大的趋势, 对营养器官的相对资源投入呈减 小的趋势。繁殖分配从海拔 $3200 \mathrm{~m}$ 处的 $20.79 \%$ 逐渐 增加到海拔4 $540 \mathrm{~m}$ 处的 $26.62 \%$; 而营养分配从海 拔3 $200 \mathrm{~m}$ 处的 $79.10 \%$ 逐渐减少到海拔 $4540 \mathrm{~m}$ 处的 $64.51 \%$ 。

\section{2 不同海拔狮牙草状风毛菊果期繁殖特征及资 源分配与植物大小的关系}

由表2可以看出, 不同海拔梯度下, 狮牙草状风 毛菊的个体大小与种子百粒质量、种子数、繁殖器 官生物量及营养分配呈正相关关系，即种子百粒质 量、种子数、繁殖器官生物量及营养分配随个体大 小的增大而增大，但这种增大的趋势在不同海拔间 有所差异，因此百粒质量、种子数、繁殖器官生物 量及营养分配与个体大小没有表现出固定的变化规 律。营养器官生物量随个体大小的增大而极显著增

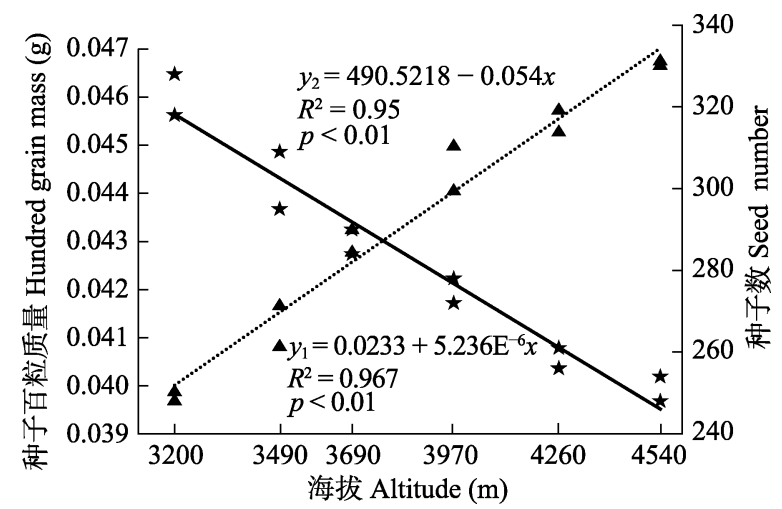

图3 狮牙草状风毛菊种子百粒质量 $\left(y_{1}, \mathbf{\Delta}\right)$ 及种子数 $\left(y_{2}, \star\right)$ 与海拔 $(x)$ 的线性回归。

Fig. 3 Liner regression between hundred grain mass $\left(y_{1}, \mathbf{\Delta}\right)$, seed number $\left(y_{2}, \star\right)$ and elevation $(x)$ for Saussurea leontodontoides.

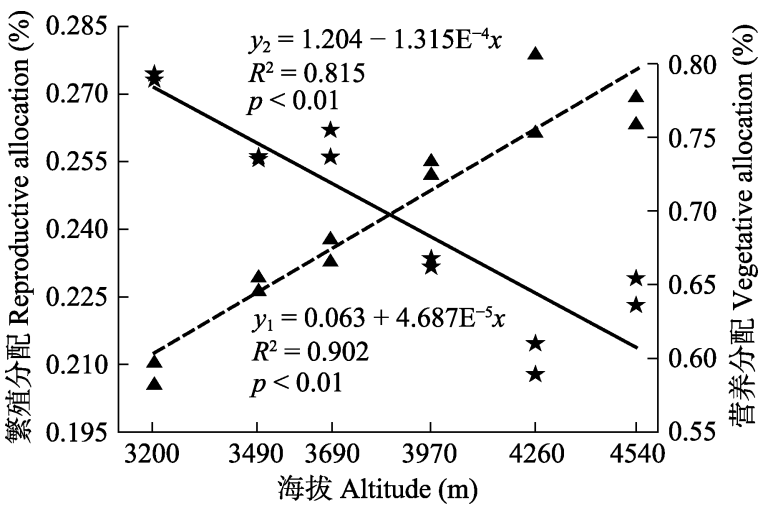

图4 狮牙草状风毛菊繁殖分配 $\left(y_{1}, \mathbf{\Delta}\right)$ 及营养分配 $\left(y_{2}, \star\right)$ 与 海拔 $(x)$ 的线性回归。

Fig. 4 Liner regression between reproductive allocation $\left(y_{1}, \mathbf{\Delta}\right)$, vegetative allocation $\left(y_{2}, \star\right)$ and altitude $(x)$ for Saussurea leontodontoides. 
表2 狮牙草状风毛菊不同海拔种群果期繁殖特征及资源分配 $(y)$ 与个体大小 $(x)$ 的回归

Table 2 Relationship between reproduction characteristics and resource allocation of population ( $y$ ) at different levels of the altitude gradient in fruiting stage and individual size $(x)$ of Saussurea leontodontoides

\begin{tabular}{|c|c|c|c|c|c|c|}
\hline $\begin{array}{l}\text { 海拔 } \\
\text { Altitude } \\
(\mathrm{m})\end{array}$ & $\begin{array}{l}\text { 种子百粒质量 } \\
\text { Hundred grain } \\
\text { mass }(g)\end{array}$ & $\begin{array}{l}\text { 种子数 } \\
\text { Seed number }\end{array}$ & $\begin{array}{l}\text { 繁殖器官生物量 } \\
\text { Reproductive organ } \\
\text { biomass (g) }\end{array}$ & $\begin{array}{l}\text { 营养器官生物量 } \\
\text { Vegetative organ } \\
\text { biomass (g) }\end{array}$ & $\begin{array}{l}\text { 繁殖分配 } \\
\text { Reproductive } \\
\text { allocation }\end{array}$ & $\begin{array}{l}\text { 营养分配 } \\
\text { Vegetative } \\
\text { allocation }\end{array}$ \\
\hline 3200 & $\begin{array}{l}y=-1.686+0.386 x \\
R^{2}=0.187, p=0.004\end{array}$ & $\begin{array}{l}y=2.259+0.338 x \\
R^{2}=0.135, p=0.200\end{array}$ & $\begin{array}{l}y=-0.275+0.418 x \\
R^{2}=0.084, p=0.066\end{array}$ & $\begin{array}{l}y=-0.216+1.157 x \\
R^{2}=0.917, p<0.01\end{array}$ & $\begin{array}{l}y=-0.281-0.574 x \\
R^{2}=0.149, p=0.014\end{array}$ & $\begin{array}{l}y=-0.220+1.161 x \\
R^{2}=0.184, p=0.006\end{array}$ \\
\hline 3490 & $\begin{array}{l}y=-1.462+0.113 x \\
R^{2}=0.057, p=0.126\end{array}$ & $\begin{array}{l}y=2.246+0.329 x \\
R^{2}=0.108, p=0.040\end{array}$ & $\begin{array}{l}y=-0.498+0.775 x \\
R^{2}=0.641, p<0.01\end{array}$ & $\begin{array}{l}y=-0.221+1.129 x \\
R^{2}=0.955, p<0.01\end{array}$ & $\begin{array}{l}y=-0.498-0.223 x \\
R^{2}=0.133, p=0.021\end{array}$ & $\begin{array}{l}y=-0.211+0.115 x \\
R^{2}=0.182, p=0.004\end{array}$ \\
\hline 3690 & $\begin{array}{l}y=-1.439+0.107 x \\
R^{2}=0.081, p=0.072\end{array}$ & $\begin{array}{l}y=2.182+0.405 x \\
R^{2}=0.173, p=0.009\end{array}$ & $\begin{array}{l}y=-0.370+0.581 x \\
R^{2}=0.265, p=0.001\end{array}$ & $\begin{array}{l}y=-0.196+1.102 x \\
R^{2}=0.916, p<0.01\end{array}$ & $\begin{array}{l}y=-0.368-0.422 x \\
R^{2}=0.160, p=0.011\end{array}$ & $\begin{array}{l}y=-0.191+0.094 x \\
R^{2}=0.076, p=0.070\end{array}$ \\
\hline 3970 & $\begin{array}{l}y=-1.419+0.102 x \\
R^{2}=0.053, p=0.154\end{array}$ & $\begin{array}{l}y=2.270+0.260 x \\
R^{2}=0.14, p=0.015\end{array}$ & $\begin{array}{l}y=-0.119+0.208 x \\
R^{2}=0.09, p=0.064\end{array}$ & $\begin{array}{l}y=-0.297+1.183 x \\
R^{2}=0.798, p=0.010\end{array}$ & $\begin{array}{l}y=-0.119-0.791 x \\
R^{2}=0.583, p<0.01\end{array}$ & $\begin{array}{l}y=-0.298+0.185 x \\
R^{2}=0.092, p=0.054\end{array}$ \\
\hline 4260 & $\begin{array}{l}y=-1.376+0.060 x \\
R^{2}=0.047, p=0.185\end{array}$ & $\begin{array}{l}y=2.375+0.064 x \\
R^{2}=0.038, p=0.196\end{array}$ & $\begin{array}{l}y=-0.229+0.299 x \\
R^{2}=0.152, p=0.013\end{array}$ & $\begin{array}{l}y=-0.341+1.192 x \\
R^{2}=0.751, p<0.01\end{array}$ & $\begin{array}{l}y=-0.226-0.704 x \\
R^{2}=0.497, p<0.01\end{array}$ & $\begin{array}{l}y=-0.343+0.196 x \\
R^{2}=0.075, p=0.091\end{array}$ \\
\hline 4540 & $\begin{array}{l}y=-1.516+0.376 x \\
R^{2}=0.231, p=0.003\end{array}$ & $\begin{array}{l}y=2.264+0.272 x \\
R^{2}=0.098, p=0.049\end{array}$ & $\begin{array}{l}y=-0.430+0.697 x \\
R^{2}=0.262, p=0.001\end{array}$ & $\begin{array}{l}y=-0.164+0.940 x \\
R^{2}=0.385, p<0.01\end{array}$ & $\begin{array}{l}y=-0.439-0.287 x \\
R^{2}=0.055, p=0.144\end{array}$ & $\begin{array}{l}y=-0.182+0.024 x \\
R^{2}=3.94 \mathrm{E}^{-4}, p=0.840\end{array}$ \\
\hline$F$ & & & & $\begin{array}{l}\text { B: } 0.790^{\mathrm{ns}} \\
\text { A: } 9.886^{* *}\end{array}$ & & \\
\hline
\end{tabular}

$\mathrm{A}$, 截距; $\mathrm{B}$, 斜率。**, 差异极显著 $(p<0.01)$; ns, 差异不显著。

A, intercept; B, slope. ${ }^{* *}$, significant difference $(p<0.01)$; ns, no significant difference.

加 $(p<0.01)$, 且截距在海拔间有极显著差异 $(p<$ $0.01)$, 表明海拔对营养器官生物量产生了直接的影 响。在海拔3 200-4 $260 \mathrm{~m}$ 间, 繁殖分配随个体大小 的增大而显著减小 $(p<0.05)$, 但在海拔 $4540 \mathrm{~m}$ 处增 大的趋势并不显著 $(p=0.144)$, 因此繁殖分配与个 体大小没有表现出固定的变化规律。

\section{3 讨论}

青藏高原的恶劣环境严重限制了植物的生长发 育和繁殖。这种压力往往通过长期适应和选择来影 响植物的生殖分配策略(Li et al., 2019)。本研究结果 显示, 随着海拔的上升, 狮牙草状风毛菊的个体大 小极显著减小 $(p<0.01)$ 。说明狮牙草状风毛菊对高 海拔地区复杂的气候环境做出了适应性的响应。产 生这种结果的原因可能如下: 第一, 青藏高原太阳 辐射强烈, 研究发现增强UV-B辐射, 会造成植物体 光合色素的减少, 从而影响有机物的产生和积累 (祁虹等, 2017)。第二, 植物个体越小, 热量损失越 小(Korner, 2009)。同时, 动物对植株的踩踏、啃食 及青藏高寒地区冰雹等因素都会使较大的植株面临 较高的危险。第三, 矮小植株所形成的温暖的花部 环境可能对结䊏率和昆虫的访花频率有促进作用 (Webb \& Shand, 1985)。与此同时, 随着海拔的升高, 狮牙草状风毛菊的繁殖器官生物量、营养器官生物 量、种子数量以及营养分配都极显著减小 $(p<$ $0.01)$, 而种子百粒质量和繁殖分配极显著增大 $(p<$ 0.01 )。毛婉殹等(2019)研究重齿风毛菊繁殖分配及
花部特征与海拔的相关性发现个体大小、营养器官 生物量与海拔呈显著负相关关系，王一峰等(2016) 研究川西风毛菊果期资源分配对海拔的响应发现 随海拔的升高个体大小、繁殖器官生物量、营养器 官生物量、种子数和营养分配都在逐渐减少，而繁 殖分配则于海拔呈正相关关系，我们的结论与之 一致。这也与张婵等(2020)的青藏高原及周边高山 地区的植物随环境胁迫程度的加强(如海拔的升 高), 植物个体大小趋于变小, 营养器官和繁殖器 官的生物量均减少的观点相符。这可能是由于在 高山地带, 可供植物从外界获取的资源总量减少。 在生存选择面前，繁殖投入被优先考虑，因此需通 过增加对繁殖性状的投入, 将有限的可利用资源 投入到繁殖结构上(繁殖分配增大), 来保证生存及 繁殖的成功率。

种子是裸子植物和被子植物特有的繁殖体，是 植物连接亲代和子代的桥梁, 也是植物生活史的起 始和末端, 对植物种群的延续具有重要意义。种子 数目和大小不仅受到性状和遗传因素协同作用的影 响, 更重要的是生态环境(如温度、湿度、土壤养分 等)对其产生的影响(Leishman et al., 2000)。在资源 贫乏、干扰性强的环境下, 较大的种子比较小的种 子具有更高的幼苗成活率(Gross, 1984; Moles \& Westoby, 2004), 而较小的种子相比较大的种子可以 传播得更远, 有助于扩大种群的分布范围(Morse \& Schmitt, 1985), 但在个体竞争上较大的种子更具有 优势，较易成为其适合区域的优势种(Leishman \& 
Murray, 2001; Lebrija et al., 2016)。本研究发现, 狮 牙草状风毛菊种子百粒质量随海拔的升高显著增加, 种子数目则呈相反的现象。这与对玉䙃 (Hosta plantaginea)、川西风毛菊等种子变异的研究结果(操 国兴等, 2007; 王一峰等, 2016)一致, 即狮牙草状风 毛菊随海拔的升高在种子数和种子大小之间做出了 “此消彼长”的适应性权衡以提高适合度。

了解植物繁殖资源分配的重点是分析个体大小 依赖的繁殖策略(Weiner et al., 2009)。本研究中, 狮 牙草状风毛菊的繁殖器官生物量、种子百粒质量、 营养分配和种子数在不同海拔高度上都与个体大小 呈正相关关系, 营养器官生物量与个体大小存在极 显著正相关关系。说明海拔高度对植物不同繁殖性 状的影响在一定程度上是依赖于个体大小的, 也就 是说海拔的变化影响了狮牙草状风毛菊植物个体大 小与其繁殖性状的异速关系。然而繁殖分配在海拔 3200-4260 m处与植株个体大小呈显著负相关关 系, 而在高海拔 $4540 \mathrm{~m}$ 处与个体大小无显著相关 关系。这有可能是因为植株本身的遗传特性及所处 的具体生境(土壤水分、土壤养分、传粉环境等)有 关。已有很多研究证明繁殖分配与个体大小呈负相 关关系(刘左军等, 2002; 赵志刚等, 2004 )。但是, 也 有人发现, 两者之间存在负相关性, 但并不显著(陈 学林等, 2009)。

\section{4 结论}

本文以分布于青藏高原高山草甸植物狮牙草状 风毛菊为研究对象, 通过样地调查和实验分析采集 数据, 从种子数、种子百粒质量、资源投入及资源 分配等方面分析和探讨海拔和个体大小对其资源分 配的影响。青藏高原地区的海拔普遍较高, 在不同 海拔梯度上环境因子发生了巨大的变化, 迫使植物 的形态特征及生理特征发生改变。果期狮牙草状风 毛菊为适应海拔升高带来的环境压力采取了减小个 体大小的模式。而百粒质量和繁殖分配随海拔的升 高而增大, 表明其将有较多的有效可利用资源分配 到繁殖结构中, 以此来保证种子在极端环境中的 生存能力及提高繁殖成功率。综上所述, 狮牙草状 风毛菊的繁殖分配伴随着海拔的变化表现出了较 好的适应性。

致谢 感谢西北师范大学生命科学学院张辉老师对 论文的帮助。

\section{参考文献}

Cao GX, Yan J, Li Y, Ji P (2007). Intra-inflorescence variation in female fitness components and seed size-number trade-off in Hosta plantaginea (Liliaceae). Journal of Southwest University (Natural Science Edition), 29, 147 150. [操国兴, 严娟, 李燕, 季萍 (2007). 玉篧花序水平 上雌性适合度成分变化及种子数量与大小权衡关系研 究. 西南大学学报(自然科学版), 29, 147-150.]

Cao GX, Zhong ZC, Xie DT, Liu Y (2005). The relationship between reproductive allocation, fruit set and individual size of Camellia rosthorniana in different communities. Acta Phytoecologica Sinica, 29, 261-266. [操国兴, 钟章 成, 谢德体, 刘芸 (2005). 不同群落中川鄂连荵茶的生 殖分配与个体大小之间关系的探讨. 植物生态学报, 29 , 261-266.]

Chen K, Yang Y, Xu L, Liu X (2020). Comparison of seed trade-off strategies among Cardiocrinum giganteum populations along an elevationinal gradient in Gaoligong Mountains. Chinese Journal of Ecology, 39, 3231-3236. [陈凯, 杨艳, 徐玲, 刘霞 (2020). 高黎贡山不同海拔大 百合种子权衡策略的比较. 生态学杂志, 39, 3231-3236.]

Chen T, Wang YF (2014). Response of reproductive characteristics of Saussurea macrota Franch. to elevation at eastern Qinhai-Tibetan Plateau. Chinese Journal of Ecology, 33，3216-3221. [陈亭, 王一峰 (2014). 青藏高原 东缘大耳叶风毛菊繁殖特征对海拔的响应. 生态学杂 志, 33, 3216-3221.]

Chen XL, Liang Y, Qi W, Su M, Du GZ (2009). Studies on the reproductive allocation, floral size and its trade-off with floral number of annual Gentiana. Acta Prataculturae Sinica, 18, 58-66. [陈学林, 梁艳, 齐威, 苏梅, 杜国祯 (2009). 一年生龙胆属植物的繁殖分配及其花大小、数 量的权衡关系研究. 草业学报, 18, 58-66.]

Feener M (1985). Seed Ecology. Chapman and Hall, London.

Gross KL (1984). Effects of seed size and growth form on seedling establishment of six monocarpic perennial plants. Journal of Ecology, 72, 369-387.

Hou QZ, Wen J, Li HC, Ren YL, Sha JH, Zhao DG (2017). Reproductive allocation of three Gentianaceae species. Pratacultural Science, 34, 1017-1023. [侯勤正, 文静, 李 昊聪, 任昱兰, 沙建华, 赵东光 (2017). 3种龙胆科植物 的资源分配对策. 草业科学, 34, 1017-1023.]

Hou QZ, Ye GJ, Ma XB, Su X, Zhang SH, Sun K (2016). Size-dependent reproductive allocation of Gentianopsis paludosa in different habitats of the Qinghai-Tibetan Plateau. Acta Ecologica Sinica, 36, 2686-2694. [侯勤正, 叶广继, 马小兵, 苏雪, 张世虎, 孙坤 (2016). 青藏高 原不同生境下湿生扁蕾(Gentianopsis paludosa)个体大 小依赖的繁殖分配. 生态学报, 36, 2686-2694.]

Jin GL (2009). Study on the Plant Ecological Adaption Strategy 
of Degraded Seriphidium transiliense Desert Grassland. $\mathrm{PhD}$ dissertation, Xinjiang Agricultural University, Ürümqi. [靳瑰丽 (2009). 伊犁绢蒿荒漠退化草地植物生态 适应对策的研究. 博士学位论文, 新疆农业大学, 乌鲁 木齐.]

Korner C (2009). Functional Plant Ecology of High Mountain Ecosystems. Science Press, Beijing.

Lebrija-Trejos E, Reich PB, Hernández A, Wright SJ (2016). Species with greater seed mass are more tolerant of conspecific neighbours: a key driver of early survival and future abundances in a tropical forest. Ecology Letters, 19, 1071-1080.

Leishman MR, Murray BR (2001). The relationship between seed size and abundance in plant communities: model predictions and observed patterns. Oikos, 94, 151-161.

Leishman MR, Wright IJ, Moles AT (2000). The evolutionary ecology of seed size. Trends in Ecology \& Evolution, 7, $368-372$.

Li GQ, Zhao PP, Shao WS, Jin CQ, Song LX, Chen YY (2019). Effect of enclosure on reproductive allocation of wheatgrass Agropyron mongolicum populations in desert steppes. Ecology and Evolution, 9, 14023-14030.

Liu ZJ, Du GZ, Chen JK (2002). Size-dependent reproductive allocation of Ligularia virgaurea in different habitats. Chinese Journal of Plant Ecology, 26, 44-50. [刘左军, 杜 国祯, 陈家宽 (2002). 不同生境下黄帚㯻吾(Ligularia virgaurea) 个体大小依赖的繁殖分配. 植物生态学报, 26, 44-50.]

Mao WY, Wang YF, Yang LL, Song WD, Ma WM (2019). Reproductive allocation and floral characteristic of Saussurea katochaete in relation to elevation. Chinese Journal of Ecology, 38，60-66. [毛婉嫕, 王一峰, 杨励龙, 宋卫 东, 马文梅 (2019). 重齿风毛菊繁殖分配及花部特征与 海拔的相关性. 生态学杂志, 38, 60-66.]

Milla R, Giménez-Benavides L, Escudero A, Reich PB (2009). Intra- and interspecific performance in growth and reproduction increase with altitude: a case study with two Saxifraga species from northern Spain. Functional Ecology, 23, 111-118.

Moles AT, Westoby M (2004). What do seedlings die from and what are the implications for evolution of seed size? Oikos, 106, 193-199.

Morse DH, Schmitt J (1985). Propagule size, dispersal ability, and seedling performance in Asclepias syriaca. Oecologia, 67, 372-379.

Qi H, Duan LS, Wang SL, Wang Y, Zhang Q, Feng GY, Du HY, Liang QL, Lin YZ (2017). Effect of enhanced UV-B radiation on cotton growth and photosynthesis. Chinese Journal of Eco-Agriculture, 25, 708-719. [祁虹, 段留生, 王树林, 王燕, 张谦, 冯国艺, 杜海英, 梁青龙, 林永增 (2017). 全生育期UV-B辐射增强对棉花生长及光合作 用的影响. 中国生态农业学报, 25, 708-719.]
Qi RL, Ma WM, Qi BY, Cao JH, Yang YJ, Ma HR, Wang YF (2019). Altitudinal variation of floral organs in Saussurea przewalskii and its relationship with the number and mass of seeds. Chinese Journal of Applied Ecology, 30, 26472653. [祁如林, 马文梅, 祁百元, 曹家豪, 杨亚军, 马海 荣, 王一峰 (2019). 弯齿风毛菊花部器官的海拔变异及 其与种子质量和数目的关系. 应用生态学报, 30 , 2647-2653.]

Sakai A, Sasa A, Sakai S (2006). Do sexual dimorphisms in reproductive allocation and new shoot biomass increase with an increase of altitude? A case of the shrub willow Salix reinii (Salicaceae). American Journal of Botany, 93, 988-992.

Shi Z, Jin SY (1999). Flora of China: Vol. 78. Book 2. Science Press, Beijing. 191. [石铸, 靳淑英 (1999). 中国植物志: 第78卷. 第2分册. 科学出版社, 北京. 191.]

Sonamtso, Wang YF, Li M, Yue YC, Li MX (2013). Reproductive allocation of Saussurea hieracioides (Asteraceae), a common species in eastern margin of Qinghai-Tibet Plateau. Chinese Journal of Ecology, 32, 1433-1438. [索 南措, 王一峰, 李梅, 岳永成, 李毛先 (2013). 青藏高 原东缘常见种长毛风毛菊(Saussurea hieracioides)的繁 殖分配. 生态学杂志, 32, 1433-1438.]

Tamagno S, Sadras VO, Ortez OA, Ciampitti IA (2020). Allometric analysis reveals enhanced reproductive allocation in historical set of soybean varieties. Field Crops Research, 248, 107717. DOI: 10.1016/j.fcr.2020.107717.

Wang HX (2012). Mechanisms of Plant Leaves Based on Leaf Surface Wettability on Rainfall Interception and Dustcapturing. $\mathrm{PhD}$ dissertation, Xi'an University of Architecture and Technology, Xi'an. [王会霞 (2012). 基 于润湿性的植物叶面截留降水和降尘的机制研究. 博 士学位论文, 西安建筑科技大学, 西安.]

Wang SY (2017). Response of Seed Storage Substances, Germination and Seedlings of 7 Dominant Gramineous Plants in Alpine Meadow to Grassland N and P Addition. Master degree dissertation, Lanzhou University, Lanzhou. [王素玉 (2017). 高寒草甸7种优势禾本科植物种子咜 藏物质、萌发及幼苗对草地 N、P添加的响应. 硕士学位 论文, 兰州大学, 兰州.]

Wang TH (2006). The Study of Plant Phenotypic Plasticity and Life-History Strategies. PhD dissertation, Northeast Normal University, Changchun. [王天慧 (2006). 植物表型 可塑性及生活史对策研究. 博士学位论文, 东北师范大 学, 长春.]

Wang YF (2009). Studies on Ecology and Biology of the Genus of Saussurae (Compositae) in the East of Qinghai-Tibetan Plateau. PhD dissertation, Lanzhou University, Lanzhou. [王一峰 (2009). 青藏高原东缘风毛菊属植物生态与生 物学研究. 博士学位论文, 兰州大学, 兰州.]

Wang YF, Jin J, Cao JH, Hou HH, Li XJ (2016). The response of Saussurea dzeurensis fruiting resource allocation to

www.plant-ecology.com 
differences in elevation. Acta Ecologica Sinica, 36, 5790-5797. [王一峰, 靳洁, 曹家豪, 侯宏红, 李篵姣 (2016). 川西风毛菊果期资源分配对海拔的响应. 生态 学报, 36, 5790-5797.]

Wang YF, Kou J, Wang WY, Ma YX, Li YY (2017). Variation of fruiting resource allocation along elevations in Saussurea kansuensis. Journal of Northwest Normal University (Natural Science), 53, 87-91. [王一峰, 寇靖, 王文越, 马 诣欣, 李怡颖 (2017). 甘肃风毛菊果期资源分配对海拔 的响应. 西北师范大学学报(自然科学版), 53, 87-91.]

Wang YF, Li M, Li SX, Guo J, Chen YP, Wang RX (2012). Variation of reproductive allocation along elevations in Saussurea stella on East Qinghai-Xizang Plateau. Chinese Journal of Plant Ecology, 36, 1145-1153. [王一峰, 李梅, 李世雄, 郭杰, 陈玉萍, 王瑞雪 (2012). 青藏高原东缘 星状风毛菊生殖分配对海拔的响应. 植物生态学报, 36, 1145-1153.]

Wang YF, Yue YC (2014). Effects of resource allocation and floral traits on the number and mass of Saussurea undulata seeds from different elevations in eastern Qinghai-Xizang Plateau. Chinese Journal of Plant Ecology, 38, 366-374. [王一峰, 岳永成 (2014). 青藏高原东缘不同海拔波缘 风毛菊资源分配及花部特征对种子数目和质量的影响. 植物生态学报, 38, 366-374.]

Webb CJ, Shand JE (1985). Reproductive biology of tree lucerne (Chamaecytisus palmensis, Leguminosae). New Zea- land Journal of Botany, 23, 597-606.

Weiner J, Campbell LG, Pino J, Echarte L (2009). The allometry of reproduction within plant populations. Journal of Ecology, 97, 1220-1233.

Wilson AM, Thompson K (1989). A comparative study of reproductive allocation in 40 British grasses. Functional Ecology, 3, 297-302.

Zhang C, An YM, Jäschke Y, Wang LL, Zhou ZL, Wang LP, Yang YP, Duan YW (2020). Processes on reproductive ecology of plant species in the Qinghai-Xizang Plateau and adjacent highlands. Chinese Journal of Plant Ecology, 44, 1-21. [张婵, 安宇梦, Jäschke Y, 王林林, 周知里, 王力平, 杨永平, 段元文 (2020). 青藏高原及周边高山 地区的植物繁殖生态学研究进展. 植物生态学报, 44, $1-21$.

Zhang DY (2000). Researches on Theoretical Ecology. Springer Press, Beijing. [张大勇 (2000). 理论生态学研究. 施 普林格出版社, 北京.]

Zhao ZG, Du GZ, Ren QJ (2004). Size-dependent reproduction and sex allocation in five species of Ranunculaceae. Acta Phytoecologica Sinica, 28, 9-16. [赵志刚, 杜国祯, 任青 吉 (2004). 5种毛莨科植物个体大小依赖的繁殖分配和 性分配. 植物生态学报, 28, 9-16.]

特邀编委: 李钧敏 责任编辑: 李 敏 